\title{
Convergence of Public Participation, Participatory Design and NLP to Co-Develop Circular Economy
}

\author{
Mark Dyer ${ }^{1} \cdot$ Shaoqun $\mathrm{Wu}^{1} \cdot$ Min-Hsien Weng ${ }^{1}$
}

Received: 23 December 2020 / Accepted: 14 June 2021 / Published online: 14 July 2021

(C) The Author(s) 2021

\begin{abstract}
The concept of a circular economy is at a crossroads. To date, it has been largely driven by topdown national or trans-national legislation such as EU Circular Economy Package or Chinese Circular Economy Promotion. Bottom-up or grassroots engagement has been minimal and innovation has been largely restricted to use of $3 \mathrm{R}$ or $4 \mathrm{R}$ frameworks to reduce, reuse, recycle materials and products or recover waste as energy. Greater implementation of a circular economy needs a paradigm shift in public attitudes coupled with greater innovation that moves from 3R to 9R framework. Building on the insights gained from the successful transition of two Scandinavian cities of Växjö and Sønderborg to becoming fossil fuel-free economies, the article explores use of natural language processing tools to create shared narratives and stories from large format public engagement that expresses common interests, values and priorities that in turn can contribute to a participatory design of a circular economy. The article uses published data from Christchurch 'Share an Idea' as a case study.
\end{abstract}

Keywords Public participation $\cdot$ Circular economy $\cdot$ Narratives $\cdot$ Natural language processing $\cdot$ Participatory design $\cdot$ Case study

\section{Introduction}

The concept of a circular economy (CE) is at a crossroads. To date, it has been largely driven by topdown national or trans-national legislation such as EU Circular Economy Package or Chinese Circular Economy Promotion. Bottom-up or grassroots engagement has been minimal and innovation has been

Mark Dyer

mark.dyer@waikato.ac.nz

Shaoqun $\mathrm{Wu}$

shaoqun.wu@waikato.ac.nz

Min-Hsien Weng

Min-Hsien.weng@waikato.ac.nz

1 School of Engineering, University of Waikato, Hamilton 3216, New Zealand 
largely restricted to use of $3 \mathrm{R}$ or $4 \mathrm{R}$ frameworks to reduce, reuse, recycle materials and products or recover waste as energy. Greater implementation of CE needs a paradigm shift in public attitudes coupled with greater innovation beyond $3 \mathrm{R}$ and $4 \mathrm{R}$ frameworks.

The paradigm shift will involve a major change in mindsets by individuals and communities to embrace the underlying principles of CE that challenges the consumerist free market agenda of the last 3 or more decades. Lessons learnt from transformation of cities towards becoming fossil fuel-free societies point to the need for 'bottom-up' conversations based on shared cultural values and interests that motivate change. In particular, ethnographic studies undertaken for the Scandinavian cities of Växjö and Sønderborg transition towards becoming fossil fuel-free economies highlight the importance of identifying common narratives to transcend political cycles [1]. In the case of Växjö, the common narrative was one of protecting the environment and restoring damaged ecosystems. In comparison, the successful transition for Sønderborg was built on a narrative of combining job creation with movement towards zero carbon emissions based on renewable energy, deployment of district heating systems and generation and retrofitting of homes, all of which were funded by a public-private partnership between local government, industry and banks.

However, creating common narratives at a neighbourhood or city scale, let alone a national scale, is a challenging task. Community engagement initiatives for new infrastructure projects typically involve consultation with relatively small groups of people via design charrettes or town hall meetings. Public participation exercises for public policy can likewise involve 10s or 100s through structured interviews or again town hall meetings. More recently, there has been a growing interest in online public consultation such as the 'Share an Idea' public conversation launched by Christchurch City Council following the 2010-11 earthquakes [2]. In this case, the public conversation focussed on the redevelopment of the central city, which attracted 106,000 contributions from residents within 6 weeks. The City Council officers were faced with the daunting task of manually interpreting the results from the consultation exercise into a document entitled 'Common Themes for Redevelopment of the Central City'. As pointed out by the bibliometric study undertaken by Dyer et al. [3], manual interpretation of public consultation runs the risk of bias and decontextualisation. There is an obvious need to complement online public consultation with automated and objective analysis of large format data sets by using emerging artificial intelligence and machine learning tools.

Taking inspiration from the success of Växjö and Sønderborg transitions towards becoming fossil fuel-free economies, the authors investigated the use of natural language processing (NLP) tools to compose 'common narratives' from large format data sets such as the 'Christchurch' 'Share an Idea' initiative. At the same time, it was recognised that there was the added opportunity to align large-scale public engagement with participatory design techniques to address major societal challenges by co-designing new services, products and infrastructure for CE transition that respond to 'user needs'. With these ambitious goals in mind, a digital platform termed 'Urban Narrative' was developed using Stanford NLP toolkits. The platform extracts key messages that contribute towards an overall narrative about shared interests. The concept has been demonstrated using published data from Christchurch 'Share an Idea'.

\section{Literature Review}

\section{Circular Economy}

The last 2 decades have seen a growing interest worldwide in the concept $\mathrm{CE}$ as an alternative approach to the dominant linear economy. The concept can be traced back to the early work of 
the environmental economists Pearce and Turner [4] and ecological economist Boulding (1966), who characterised an economy as a circular system required for the sustainability of human life on Earth. In parallel, CE evolved from General Systems Theory and Industrial Ecology [5].

As critiqued by Geissdoerfer et al. [6] CE has gained considerable momentum since the introduction of national and trans-national legislation in the form of Chinese Circular Economy Promotion Law and the European Union Action Plan for the Circular Economy [7, 8]. However, CE is still in its infancy and typically framed as a closed-loop concept involving elimination of waste within a new business model. This relatively narrow focus on elimination of waste is further highlighted by Ghisellini et al. [9] and Kirchherr et al. [10], who observed that $\mathrm{CE}$ mainly emerges in the scientific literature through principles of $3 \mathrm{R}$, namely reduction, reuse and recycle of waste products or by-products that evolve to $4 \mathrm{R}$ through adoption of term recovery (typically in the form of energy). This approach is underlined by Chinese $\mathrm{CE}$ Promotion Law which defines $\mathrm{CE}$ as a generic term for the reducing, reusing and recycling activities conducted in the process of production, circulation and consumption $[11,12]$. This approach has led China to develop the largest network of EIP Eco-Industry Parks (60 EIP established between 2001 and 2011) that foster industrial symbiosis through physical sharing of by-products between manufacturing companies such as waste heat or waste products.

In these industrial systems, industries exchanged and shared material resources (material, water, energy and by-products) as part of 'industrial symbiosis'. Likewise, a similar approach was adopted by Japanese eco-towns program in the 1990s that combined urban and industrial centres in symbiosis projects driven by geographical proximity [13]. The objective was to achieve zero emissions goals, reduce landfilling waste and revitalise the local textile industry [13]. This emphasis on waste reduction was further highlighted by Kirchherr et al. [10] who identified the most common conceptualisation of $\mathrm{CE}$ was found to be a combination of reduce, reuse and recycling as part of a $3 \mathrm{R}$ framework that operated at micro level (products, companies, consumers), meso level (eco-industrial parks) and macro level (city, region, nation and beyond).

Alternatively, Potting et al. [14] have advocated circularity strategies based on a 9R framework as shown in Fig. 1. The approach aims to increase circularity within product chains through smarter product design and re-manufacture that focuses more on product functions or shared services. Interestingly, the study considered socioinstitutional barriers to be the major obstacle for increasing circularity rather than shortfall in technology. The authors concluded that a shift in public mindset was needed to advance CE transitions. In particular, socio-institutional factors in the form of written and unwritten rules, customs and beliefs were found to be both barriers and motivators for CE transition and increased circularity. In comparison, the study found technological innovation played a limited role in CE transition.

Coincidentally, the study by Dyer et al. [15] explored similar issues when attempting to implement a Triple Zero waste strategy for NATO military camps. Again, the study identified poor engagement by military personnel as the principal obstacles to reducing waste generation, water and energy consumption at military operations, not a lack of technology. The study offered a practical strategy for implementing a Triple Zero approach by raising awareness and engagement of participants in the following areas.

(a) Create Identities. By creating identities of sustainability, where all of the elements involving society, environment and economy are present and intertwined; communities begin to recognise sustainability as a concept that affects everyone's lives, families, 


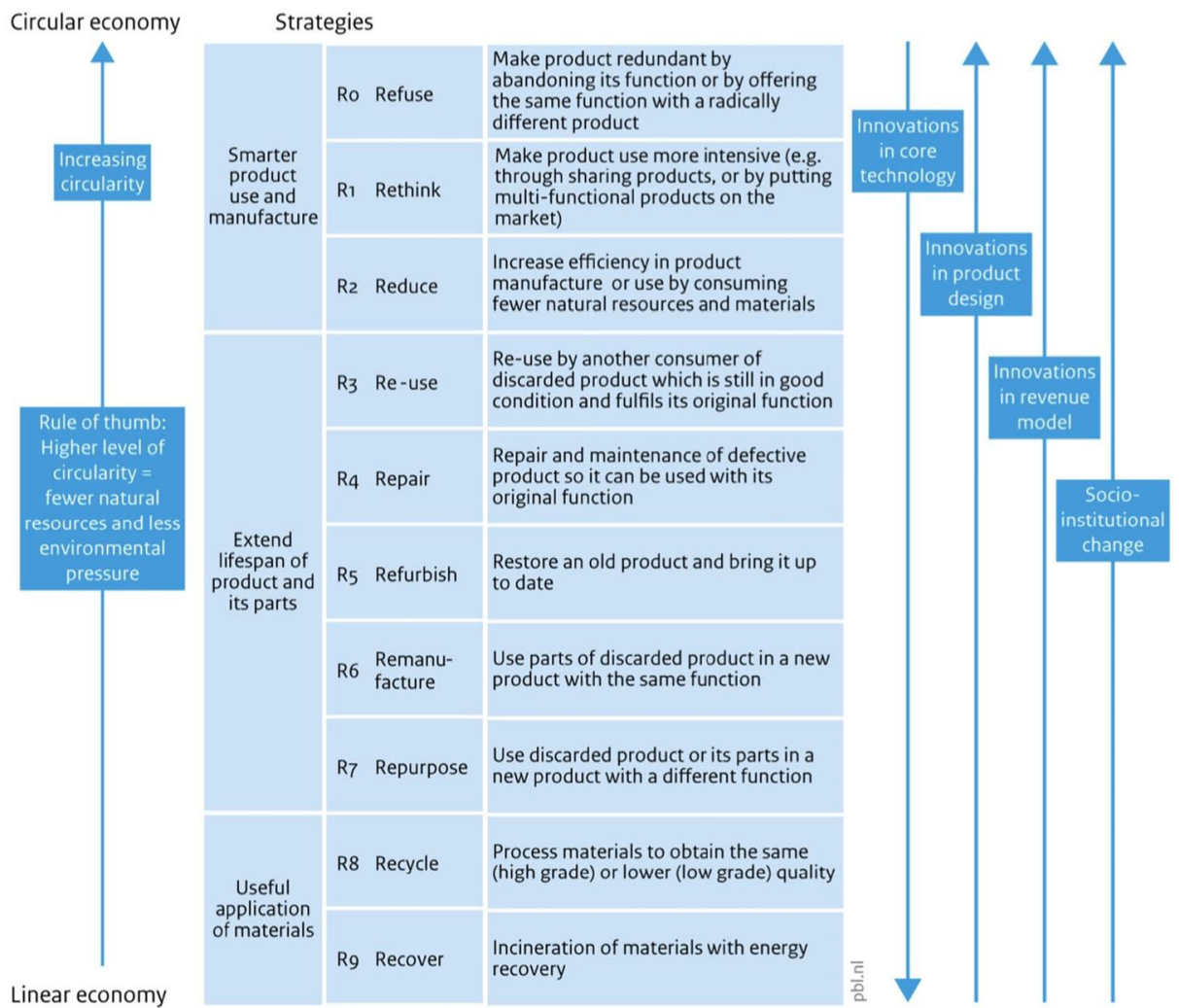

Fig. 1 Increasing circularity via 9R framework [14]

children, future and happiness and which needs to be communicated in simple language that everyone can understand.

(b) Tell Stories. By listening, telling and retelling stories about how change can happen and has successfully happened, shared narratives can become powerful human motivators for action. There are countless examples about how communities have succeeded in making a positive change, by reducing carbon consumption and climate gas emissions when dealing more imaginatively with energy, waste and water or other issues that protect the environment in a wider sense.

(c) Empower Individuals. Empowering individuals who already feel passionate and committed to the issue. These champions are invaluable co-workers in making change happen, who are often having hard time being heard and obtaining support for their efforts

\section{Public Participation vis-a-vis Participatory Design}

Having recognised the importance of public engagement for CE transitions, it is critical to understand the elements that led to successful engagement. The seminal works by Fung [16, 17] characterises public participation as having three distinct elements (or dimensions), namely who are the participants, how the participants communicate and what is the impact of the 
participation exercise. The approach is developed further as a three dimensional 'Democracy Cube'. In a similar vein, the later work by Nabatchi [18] advocated a framework for designing public participation comprising eight elements (or propositions). The main characteristics of both frameworks for public participation can be summarised as follows:

- Deliberative modes of communication that avoid one-way communication

- Collaborative processes focussed on common interests (values) as opposed to fixed positions

- Shared decision-making to resolve values-based policy conflict

- Provision of information to better inform participants and aid good quality decisionmaking

- Recruitment strategies that are representative of diverse stakeholders and avoid bias

Yet as recognised by Fung [16, 17], Nabatchi [18], Gleeson and Dyer [19], one of the major challenges with participatory mechanisms is the creation of collaborative two-way processes for representative groups of participants to critically define and identify possible solutions whether it be in the public policy arena or design of a new product. Traditionally, the scale of the deliberative process is a controlling factor. As observed by Nabatchi (loc cit), large format processes typically take place in town hall style meetings that tended to foster one-way communication.

In comparison, participatory design processes engage the public in the form of the 'user' as a full design partner, as shown in Fig. 2. This approach empowers the 'users' to be active participants in the design process. Hence, the designer becomes a facilitator or what Ehn [21] describes as a responsive designer, one who alternates the leadership roles in a project depending on whose skills are most relevant, whilst at the same time keeping all participants involved. Intriguingly, Dewey [22], as twentieth-century thought leaders for public participation, implicitly recognised the overlap between public participation mechanisms and participatory design by once remarking that 'the man who wears the shoe, not the shoemaker, knows best where it pinches'. Consequently, there is a great deal of potential commonality between public participation and participatory design, especially where the two aim to empower the 'user'. This provides the theoretical foundations to explore ways of integrating both processes to facilitate a paradigm shift towards $\mathrm{CE}$ transition.

At the same time, it is important to recognise that design thinking is an iterative process that starts with understanding the needs of end users as illustrated in Fig. 3 [15]. In participatory design, this is achieved by involving the user directly within the design team as a design partner, where the design partner identifies their needs in design forum/workshop. The challenge for large-scale initiatives such as $\mathrm{CE}$ is upscaling engagement beyond traditional numbers of participants from 10 s or 100 s to 10,000 s plus. Taking inspiration from the success experienced by Växjö and Sønderborg, a digital platform(s) has been developed using natural language processing (NLP) tools to upscale large format public participation to identify public 'interests' and 'fixed positions' as part of a people-centred design process for new products, services and infrastructure to aid CE transition.

\section{Natural Language Processing}

The convergence of public participation techniques with participatory design methods offers the prospects of upscaling public consultation as a two-way process to create common narratives based on 'shared interests' using natural language processing (NLP) tools [23]. Examples already exist of NLP being used on popular social network platforms to analyse 


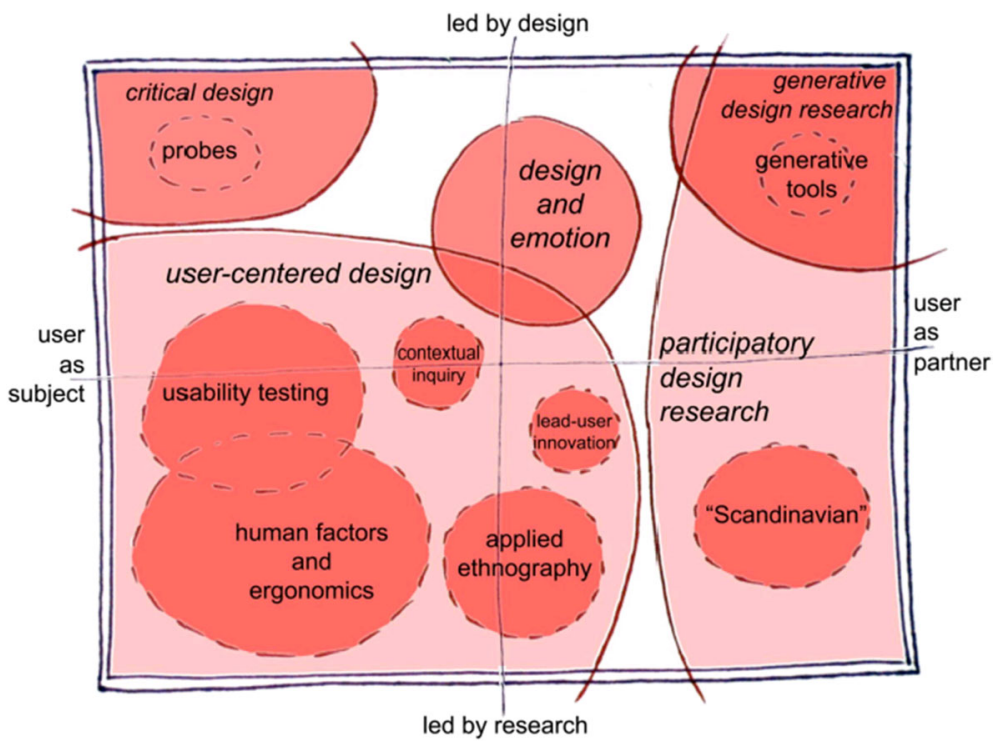

Fig. 2 Spectrum of people-centred design practices [20]

comments on products, movie reviews or restaurant ratings for marketing purposes. More recently NLP has made rapid advances using deep learning techniques to develop automatic learning procedures $[24,25]$ and in particular neutral networks including word embeddings to capture semantic properties of words or semantic role labelling (such as an agent, goal or result) to words or phrases to find the meaning of the sentence [26, 27].

For this study, Stanford NLP Core toolkits [28] were employed for several reasons. Firstly, the individual modules were developed using neural language models that gave reliable language analysis results. Secondly, the toolkits use common and uniform APIs that reduce the workloads of system integration. Lastly, central language processing analyses are

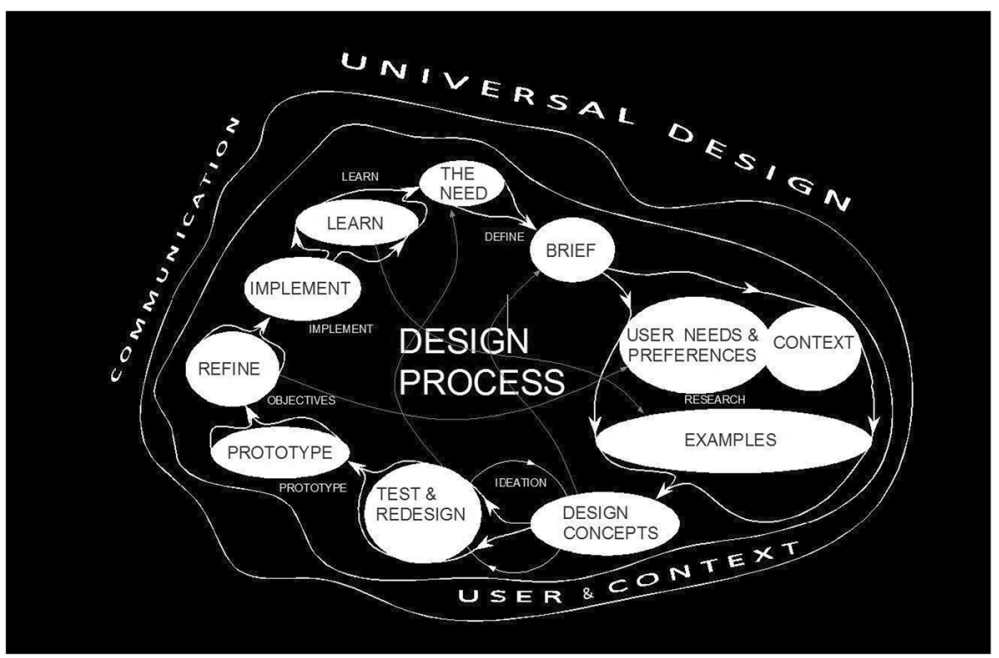

Fig. 3 Universal design process (after [15]) 
supported by the toolkits that both identify phrases from a sentence and capture compositional structure of phrases, e.g. the parser extracts the noun phrase 'buildings that are accessible to all', in addition to a single noun word 'buildings', to give more sensible meanings [29].

\section{Methodology}

\section{General}

With the aim of creating data stories from NLP analysis of large public format data, a digital platform 'Urban Narrative' was developed using systems architecture comprising 4 phases as illustrated in Fig. 4.

\section{Phase 1: Data Storage and Cleaning}

Phase 1 extracts text from various file types (e.g. word documents, pdfs and web pages) and encodes each public quote as a single text, and all the texts are collectively stored as a dataset in a repository or Cloud storage. Since the raw texts may well contain irregularities that would cause NLP toolkits to produce inaccurate result, a series of text cleaning and corrections are conducted that include the following:

- Replacing tabs and duplicated spaces with a single white space, to ensure every word is separated by one space

- Replacing abnormal quote marks, such as back quote and double quotes, with the regular quote mark, to ensure every mark remains the same across the entire text

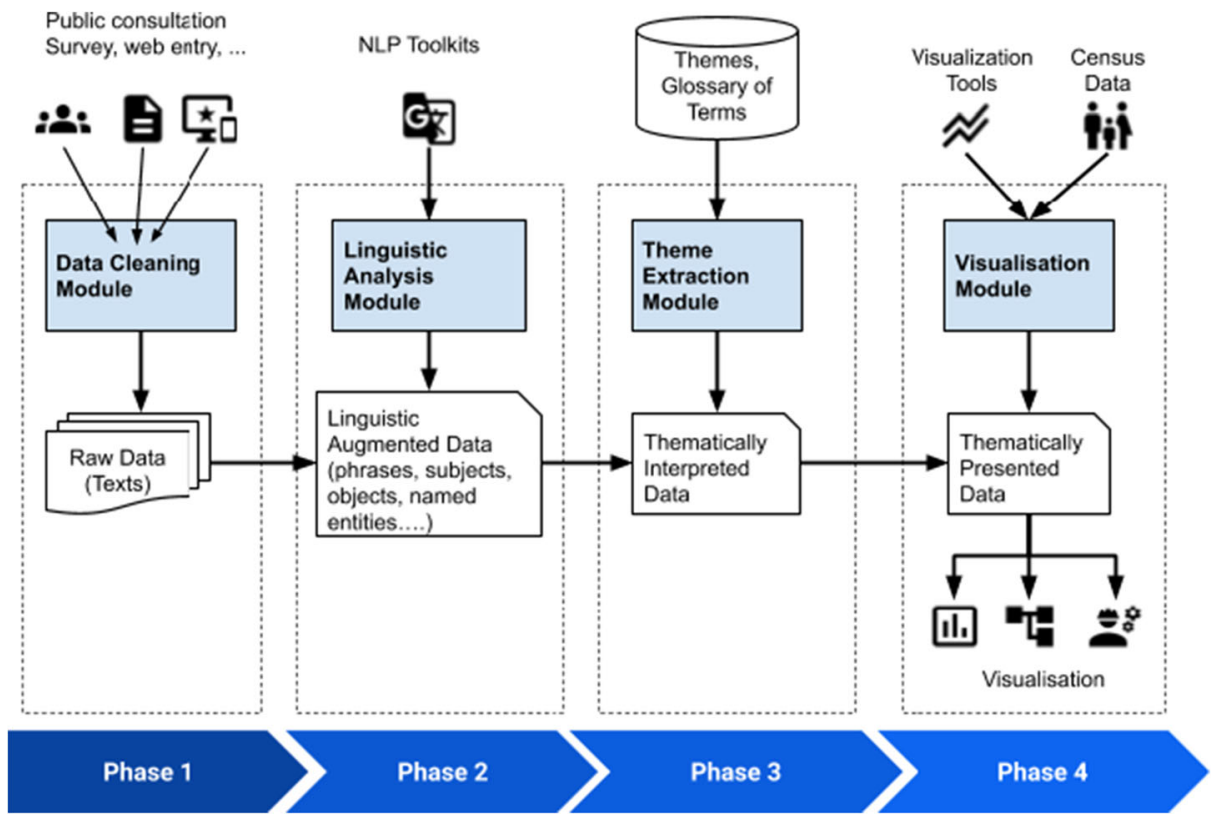

Fig. 4 Systems architecture for 'Urban Narrative' 
- Replacing hyphen (-) with commas to unify the symbols

\section{Phase 2: Linguistic Augmentation}

Phase 2 applies Stanford NLP Core toolkit to parse the individual sentences into structured linguistic data [28], where each sentence is divided into words and each word tagged with part-of-speech label to classify the word as a noun, verb, object etc. In particular, the process involves three steps. Step 1 splits the texts into individual sentences. The text 'I want composting toilets in most homes so the sewerage will not be a problem in the next earthquake.' becomes two sentences 'I want composting toilets.' and 'So the sewerage will not be a problem in the next earthquake.' Step 2 tokenises each sentence and assigns part-of-speech (POS) tags to words in a sentence. Figure 4 shows the tagged version of the sentence 'I want composting toilets.' with POS tags at the top where 'PRP' stands for personal pronoun, likewise 'VBP' for verb, 'VBG' for gerund verb that acts like noun and 'NNS' for plural noun. Figures 5 and 6

Subsequently, Step 3 extracts four types of linguistic data as follows.

1. Verbs and nouns (e.g. want as a verb and toilets as a noun respectively) are identified based on the POS tags associated with each word.

2. Noun and verb phrases are extracted using Stanford Constituency parser [29].

A noun phrase must have at least one central noun word (e.g. toilets) that is sometimes modified by other words (e.g. composting). Two or more noun phrases can be merged into a single noun phrase, the following sentence contains two noun phrases 'recycling bins' and 'more trees'. To capture a broad semantic meaning, 'recycling bins and more trees' is treated as one noun phrase.

"I want recycling bins and more trees"

A verb phrase constitutes a main verb (e.g. want) followed by noun phrases (e.g. green spaces) or sentence segments. For example, the sentence segment "to see more rainwater reused for irrigating green spaces" in turn contains another verb phrase (e.g. reused for irrigating green space) in the following sentence.

"I want to see more rainwater reused for irrigating green spaces"

3. Subject, object, and their relations are extracted by the Stanford NLP Open Information Extractor. The dependency graph indicates 'I' as the subject and 'electric car charging stations' as the object, and the verb 'want' connects the subject and object.

Fig. 5 Part-of-speech tagged sentence

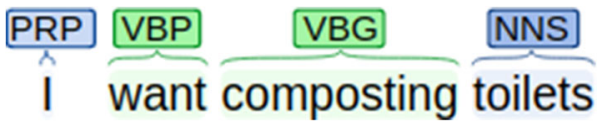




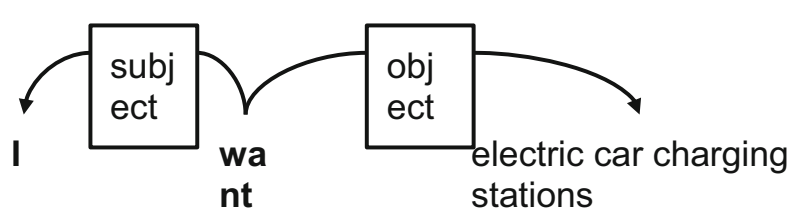

Fig. 6 A dependency graph for 'I want electric car charging stations'

4. Named entities are the names of things, detected by Stanford NLP Named Entity recogniser in a text. Entities are labelled with entity types such as person (e.g. Jacinda Ardern), title (e.g. prime minister), or country (e.g. New Zealand).

\section{Phase 3: Thematic Interpretation}

Phase 3 provides a thematic interpretation of the augmented text data by attempting to differentiate between expressions of shared 'interests' compared with 'fixed positions' linked to thematic topics pertinent to $\mathrm{CE}$.

\section{Differentiating Between 'Interests' and 'Fixed Positions'}

To differentiate between participants' 'interests' compared to 'fixed positions', all the sentences were examined for phrases beginning with the phrases 'I want', 'I like/love' or 'I believe/think'. The verb 'want' was interpreted as stating a 'fixed position' compared with the verbs 'like/love/believe/think' labelled as expressing an 'interest'. The work by Nabatchi (loc cit) deemed it important to differentiate between these two standpoints because 'fixed positions' commonly lead to adversarial environments, whereas expressions of 'interest' foster collaborative work. The following example sentences from Christchurch 'Share an Idea' data illustrated 'fixed positions'.

'I want tecseed ingheimsimmdateroreutsedsfor irrigating green spaces.'

Whereas shared 'interests' expressed using the phrases 'I + like/love' or 'I + believe/think' plus an object clause are shown below.

'I would like to use some of the bricks and material from buildings lost in the quake in new buildings.'

'I would love to see the inner city car free with a lot of cycle ways, bus lanes and pedestrian only areas.'

'I think that wind and solar generators should be installed on ALL CBD buildings.'

'I believe that more green alternatives should be utilised to improve essential services

e.g. power and sewerage.'

Exploring Thematic Topics

Next, sentences were examined in relation to a predetermined glossary of terms used to characterise functions of urban infrastructures. The glossary of terms were generated using 'word embedding' techniques to represent words as vectors to calculate surrounding words with the similar meaning or similar vector score. For each two seed terms fed into the 'word 
embedding' model, ten similar or related words were output. For example [train and rail were combined to search for the similar words and produce a collection of representative terms of public transport, comprising express, tram, freight, railway and intercity. Three popular word embedding models were trialled, namely Wikipedia Word2Vec [30], Google News and Twitter Wikipedia Word2Vec which were found to produce the best results.

\section{Phase 4: Communication and Visualisation}

Phase 4 visualises the results from Phase 3 using a combination of chord charts, word trees, design personas and design briefs that together can compose a common narrative using data storytelling techniques. The first two techniques are illustrated in the following case study for Christchurch 'Share an Idea'. Examples of design personas and design briefs for use in collaborative urban design are presented in [31].

\section{Results}

\section{Christchurch 'Share an Idea'}

As mentioned earlier, Christchurch 'Share an Idea' public consultation was undertaken in response to The New Zealand Government's Canterbury Earthquake Recovery Act 2011 (CER Act) that required Christchurch City Council (CCC) to develop a draft recovery plan for the central city, in 9 months (including public consultation), whilst CERA separately developed a recovery strategy for the Christchurch metropolitan area. The 'Share an Idea' website generated 58,000 hits and engaged the public in four key areas: move (transportation), market (business), space (public place and recreation) and life (mixed uses). The campaign also used traditional and other social media networks to gather public contributions. The unprecedented level of public participation generated 106,000 ideas over 6 weeks, and these informed the development of the Draft CCP [32]. Of which, 2,740 quotes (58,100 words) from the original texts were published in the Christchurch Common Themes (CCT) report [2], which has been used in this study.

Having extracted and 'cleaned' the data set, the linguistically augmented data set was used to identify shared 'interests' or 'fixed positions' about topics relevant to $\mathrm{CE}$ that included waste, water, transportation and energy. Individual contributions were extracted using automated glossary of terms together with personal pronouns and verbs that expressed personal 'interests' in the form of 'I love/like ...' and 'I think/believe ...' compared with 'fixed positions' in terms of 'I want ...'. A selected set of contributions are shown in Tables 1 and 2. The information provides a useful insight into topics of interest for the Christchurch community as well as proposed solutions. In terms of waste minimisation, Table 1 reveals a wide interest in alternative ways of decentralising treatment of sewage using composting methods or collecting rainwater for household consumption. Likewise, suggestions were made about reusing demolition materials for rebuilding of the central city. In relation to $9 \mathrm{R}$, the contributions offered useful suggestions on rethinking centralised management of sewage (R1), reuse (R3) and repurposing (R7).

Similarly, Table 2 shows a public appetite for more public transport, cycling, pedestrianisation and provision of electric vehicles together with sharing of vehicles. Each of these suggestions relates directly to different aspects of the $9 \mathrm{R}$ circulatory framework 
Table 1 Christchurch 'Share an Idea' selected public contributions on topic of waste management

'I would like to use some of the bricks and material from buildings lost in the quake in new buildings so we can still have our heritage and remember.'

'I want More green space integrated with stormwater treatment systems (the Avon River currently receives vast amounts of untreated stormwater filled with various contaminants).'

'I want to see composting toilets being the norm in the whole of Christchurch, they need to be subsidised by the $\mathrm{CCC}$ so that everyone can afford to put one into their home or business. This reduces the need for a complex and very costly sewerage system.'

'I want Decentralisation of the sewage system. Alternative disposal methods investigated and implemented. Alternate energy systems devised'

'I want each house to have a minimum of a 1,000 litre drinking water tank, a 30,000 litre tank for garden use, share $\overline{\text { between } 2}$ or 3 houses.'

proposed by Potting et al. [14] albeit on a large urban scale. However, listing individual contributions in this way provides a only fragmented view of the community engagement, well removed from the conversation proposed by Christchurch City Council when launching 'Share an Idea'. To examine how a two-way conversation could be facilitated, the study explored the use of 'Word Trees' and 'Chord Charts' to visualise future community conversations.

\section{Christchurch 'Word Tree' for CE}

To explore community conversations from Christchurch 'Share an Idea' about future management of waste, water and transportation for the Central City Centre, 'Word Trees' were constructed using Google Chart. The diagrams were plotted using sentences comprising expressions of 'interests' in the form of 'I like/love ... ' or 'I think/believe ...' compared with 'fixed positions' conveyed as 'I want ...'. The resulting Word Trees are illustrated in Figs. 7 and 8 for waste management and transportation, respectively. Even though the public consultation was centred around the broad topic of rebuilding the city centre after major earthquakes, the topics of interests were very pertinent to CE. In the case of waste management, the Word Tree in Fig. 7 indicates a strong level of feeling towards 'wanting' change with an emphasis on sewage and composting. In comparison, Fig. 8 indicates an interest in replacing cars with more cycling, walking and public transport that is ideally electric driven. Furthermore, there were comments on more efficient use of space, especially for car parking. All of these suggestions for waste minimisation and alternative modes of transport align with opportunities to increase circulation within a 9R framework proposed by rethinking (R1), reusing (R3), refurbishing (R5) or repurposing (R7) as listed in Fig. 1.

Table 2 Christchurch 'Share an Idea' selected public contributions on modes of transportation

\footnotetext{
'I want cycleways along the river, to encourage cyclists and not cars.'

'I want free bike usage for central city transport'

'I would love to see the inner city car free with a lot of cycle ways, bus lanes and pedestrian only areas.'

'I want integrated bus, light rail, rail tram and bicycle transport.'

'I want electric buses, within four avenues to reduce pollution and noise'

'I want little mini electric buses for transport around around the inner city and remove all cars'

'I want cycle lanes, pedestrian, car parking, public transport, cycle parking.'

'I want pedestrian friendly streets, priority over cars when crossing streets, like in new york city'

'I want public transport that is more reliable than a bus light rail monorail subway etc free car parks in outlying suburbs to allow commuters and workers to drive to these points for easy and fast access to the centre city'

'I want a transport network that makes it easy to use public transport to get into the city.with children/pushchair.'
} 


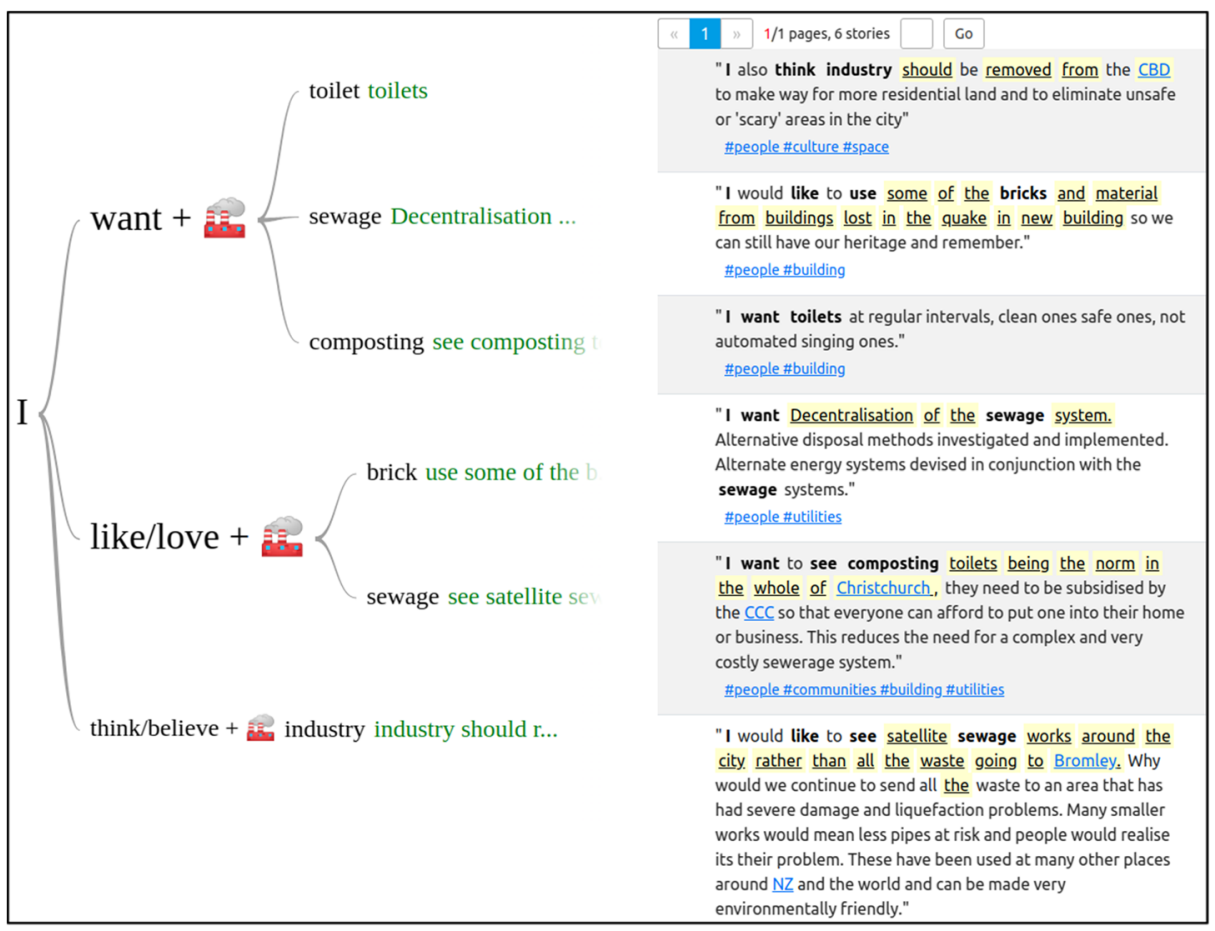

Fig. 7 Word Tree for Christchurch 'Share an Idea that displays fixed positions expressed as 'I want ...' compared with shared interests conveyed as 'I like/love...' or 'I think/believe ...' about waste minimisation and reuse

\section{Christchurch 'Chord Chart'}

The second approach used to interpret key messages from Christchurch 'Share an Idea' involved constructing Chord Charts. The images were plotted using D3.js open source library to illustrate inter-relationships between different aspects of urban infrastructures that impact on CE. The terms 'Soft and Hard Urban Infrastructures' were introduced by [31] to represent the physical utilities, buildings and spaces as 'Hard Infrastructure' compared with administrative, social and personal characterised categorised as 'Soft Infrastructure'. The approach was adopted because an initial examination of 'Share an Idea' data set showed a public awareness of connections or disconnections between 'Soft and Hard Urban Infrastructures' that affected livelihood and liveability, such as night shift workers needing to travel home or single parents with children needing easy access to recreation facilities and schooling.

The resulting Chord Charts from Christchurch 'Share an Idea' are displayed in Fig. 9. The main Chord Chart on the left hand side illustrates the multiplicity of views expressed connecting different aspects of 'Soft and Hard Urban Infrastructures'. The width of the chord indicates the relative proportion of contributions received for that particular combination of 'Soft and Hard Urban Infrastructure'. For example, there is a noticeably wide chord representing participant views about connections between People as 'Soft Infrastructure' and transport/buildings as 'Hard Infrastructure. The online application allows the individual contributions to be viewed by clicking on the relevant chord. For example, the Chord connecting People and Transport captured views and preferences about different modes of 


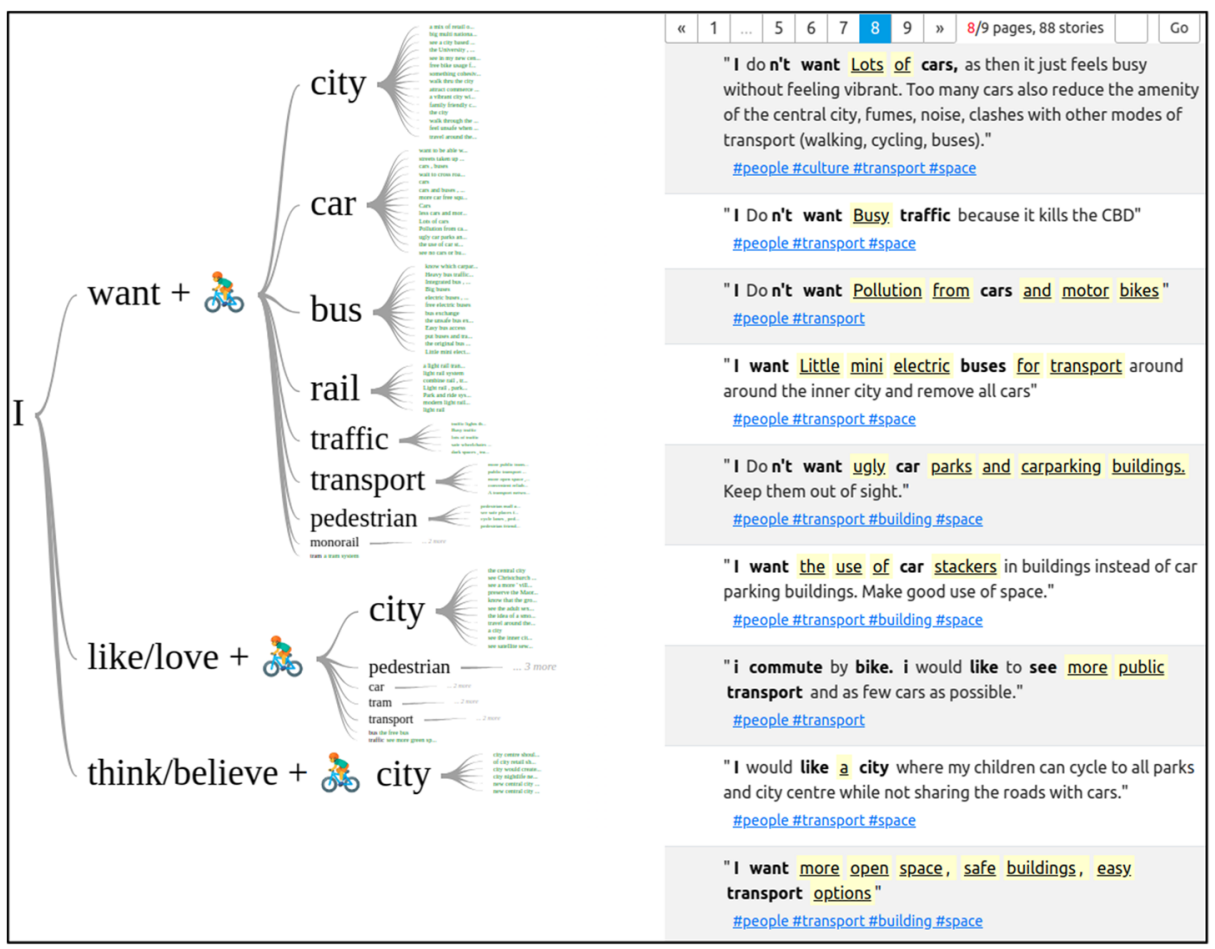

Fig. 8 Word Tree for Christchurch 'Share an Idea' displaying fixed positions expressed as 'I want ...' compared with shared interests conveyed as 'I like/love...' or 'I think/believe ...' about alternative modes of transportation in the central city.

transportation as documented in Tables 2. Ultimately, both graphical techniques allow public contributions to be processed and displayed in real time as part of a dynamic deliberative process.

\section{Discussion and Conclusions}

Although the Christchurch case study was broader than CE transitions, the size and complexity of the consultation exercise demonstrates the ability of NLP toolkits to identify personal interests (likes, beliefs, preferences) compared with fixed positions (wants, demands) about a wide range of topics pertinent to $\mathrm{CE}$ transitions. At the same time, the study raises a number of important issues worth discussing with regards to sharing of power for decision making, encouraging discussions about 'interests' rather than 'fixed positions' and the need to obtain engagement from representative sections of society.

\section{Convergence of Public Participation and Participatory Design}

The main goal of the study was to investigate whether NLP tools provide a means of converging public participation for public policy with participatory design methods to create a change in mindset and opportunity to design new services and products for $\mathrm{CE}$ transitions. 


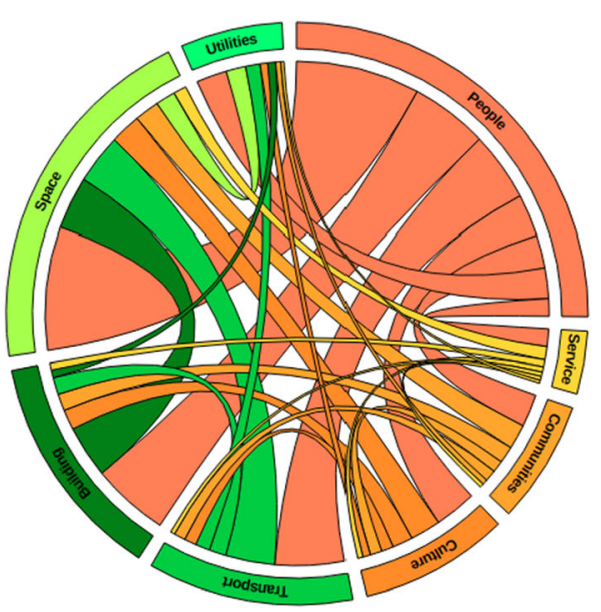

(a)

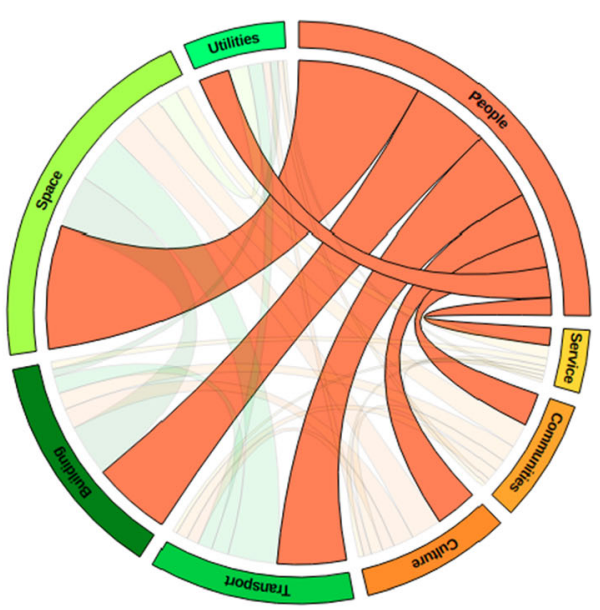

(b)

Fig. 9 Chord Chart displaying perceived connections between 'Soft and Hard Urban Infrastructures' expressed in public contributions for Christchurch 'Share an Idea'

The lessons learnt from Christchurch 'Share an Idea' show that the online public consultation was readily supported by the community, albeit under emergency conditions following the devastating earthquakes. The grassroots process proposed several important design preferences for the rebuild such as limiting the building height in the Central City to six stories. However as explained by Brand and Nicholson [32], many of the grassroot ideas stemming from the grassroots initiative fell foul of a top-down Central Government bureaucracy. In this case, CERA took complete control for the recovery plan through a top-down exercise conducted behind closed doors [33]. The bureaucratic process attracted considerable criticism with subsequent research revealing that CERA was both incapable and unwilling to engage effectively with the public [34]. Not surprisingly, public perceptions of the way the recovery was managed were perceived as being very poor, with up to $80 \%$ of the people living in Christchurch holding a negative view [34]. Reasons for this are many and are likely to reference a person's experiences of dealing with their own circumstances. But overall, Christchurch 'Share an Idea' appears to have been a lost opportunity to facilitate a genuine collaborative process for the rebuild that could readily embrace many of the underlying concepts of $\mathrm{CE}$ embedded in the public consultation as documented in Tables 1 and 2 .

In marked contrast, the strategies adopted by the cities of Växjö and Sønderborg emphasised the importance of ongoing public consultation and engagement to reinforce community narratives based on core values that underpinned one of the pillars of sustainable development. Based on these lessons learnt, in each case, the convergence of Public Consultation with Participatory Design to motivate a change in public mindset needs a transparent sharing of power between 'top-down and bottom-up' processes to facilitate ongoing two-way deliberative discussion supported by willingness to trial and modify novel solutions. This is where AI NLP-driven real-time public consultation provides a means to create ongoing community narratives based on shared 'interests' to aid design of public policy and design of new services, products and infrastructure. 


\section{Two-Way Modes of Communication for Shared Decision-Making}

With regard to participatory design, it is worth highlighting that participatory design is founded on two complementary values, the first being the right to participate in design activities and the second a means of bringing 'tacit' or non-discursive knowledge of users into design thinking. Hence, without adequate sharing of authority, the public are potentially excluded from the design process and all the knowledge and insight that they can bring. As mentioned earlier, the renowned political scientists Dewey [22] remarked that 'the man who wears the shoe, not the shoemaker, knows best where it pinches'. This insightful comment goes to the heart of participatory design. To be successful, it requires sharing of authority as illustrated in Fig. 10 and recognition that a design process is iterative. In practice, this means devising feedback systems to facilitate a two-way dialogue that is both valid, respectful and representative of the community, whilst at the same time creating a less static and more dynamic environment to trial prototypes before selecting more permanent solutions.

\section{Collaborative Design Processes Focussed on Shared 'Interests' for CE Transition}

Christchurch 'Share an Idea' initiative illustrates how well-meaning public consultation can unwittingly encourage the public to take up 'fixed positions' on topics using the phrase 'I want ...' compared with shared 'interested' expressed using phrases 'I love/like ...' or 'I think/ believe ...'. At the same time, it was intriguing to observe that phrases 'I want ..' commonly related to objects, whereas the phrases 'I think/believe ..' or 'I love/like ...' often related to less tangible issues such as environment or aesthetics. The result indicates a need for careful design of public consultation to encourage greater expressing of shared 'interests' rather than 'fixed positions'. With hindsight, it would have been more valuable to seek the public's cultural values and beliefs first and then encourage ideas or solutions about desired qualities for $\mathrm{CE}$ transitions. This would provide designers (e.g. architects, urban planners, engineers or product

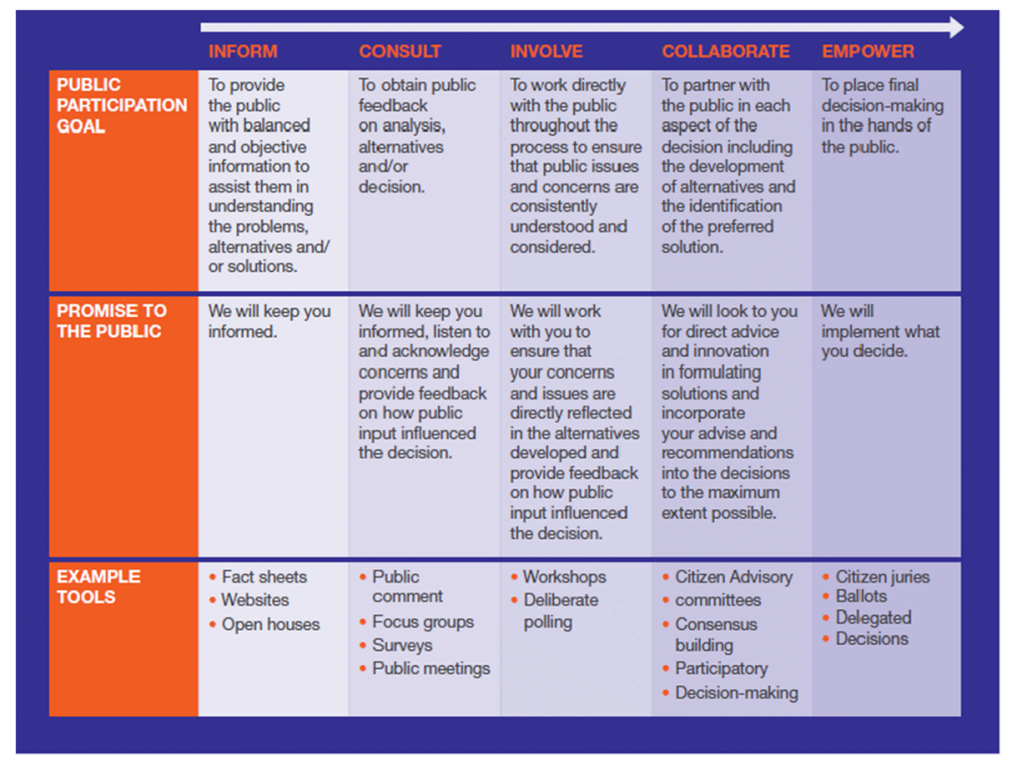

Fig. 10 International Association for Public Participation (IAP2) Spectrum of Public Participation 
designers) with more accurate information and knowledge about 'users' needs to enable them to ideate people-centred solutions.

\section{Recruitment of Representative Stakeholders to Avoid Bias}

Lastly, the level and diversity of engagement for public consultation exercises can vary considerably ranging from state-based participants (e.g., expert administrators and elected representatives), to mini-publics (e.g., professional or lay stakeholders, or randomly selected, self-selected or recruited individuals) and to diffuse members of the public [17]. The use of NPL implies an online recruitment which can influence the type of participants. In the case of Christchurch 'Share an Idea', online engagement was supplemented by in person engagement (via town hall meetings, interviews and written submissions) to broaden the range of participants. Attracting engagement from a broad range of participants is crucial to foster transformational change at scale. It becomes even more important when attempting to construct design personas that represent different socio-demographic groupings. Partly for that reason, it would be valuable where possible to connect this type of public consultation exercise with census data subject to ethical and privacy approval.

\section{Summary}

Inspired by the examples set by Växjö and Sønderborg use of community narratives to transition towards a fossil fuel free economy, the study has demonstrated the potential for NLP toolkits to analyse large format public consultation datasets to identify participants individual 'interests' and 'fixed positions' using data storytelling tools for a community wide discussion to take place in real time complex issues across a broad spectrum including CE. There are further opportunities not explored in this prototype study to extend the capability of the digital platform by linking to socio-demographic information to create design personas to aid participatory design processes to rethink product chains within a 9R strategic framework. There is also an opportunity to provide additional information about key issues via online information sources such as Wikipedia.

However, for the digital platform to be effective, there are a number of issues that need addressing. The first is sharing of authority for decision-making. Governing bodies are often reluctant to share authority for a host of different reasons. Likewise, it is crucial to focus on the public's 'interests' in the form of shared cultural values and beliefs rather than 'fixed positions' often in the form of solutions. This means designing public consultation processes to guide participants towards firstly identifying interests in terms of underlying values by concentrating on the 'why' not 'what'.

Finally, the study highlighted the commonality between public participation processes and participatory design as recognised by Dewey, which can be combined to engage in large scale rethinking of product chains and services to increase circularity as advocated by $9 \mathrm{R}$ strategic framework. In this scenario, the identification of participants' interests (values) and even positions (solutions) via NLP analysis provides the core insights about 'users' needs to aid design thinking to re-imagining future tangible and intangible product chains.

Acknowledgements The article originates from a keynote lecture presented at 'Closed Cycles' online conference hosted by International Ecological Engineering Society, Switzerland, September 2020. 
Code availability Not applicable.

Data availability Not applicable.

\section{Declarations}

Competing interests The authors declare no competing interests.

Open Access This article is licensed under a Creative Commons Attribution 4.0 International License, which permits use, sharing, adaptation, distribution and reproduction in any medium or format, as long as you give appropriate credit to the original author(s) and the source, provide a link to the Creative Commons licence, and indicate if changes were made. The images or other third party material in this article are included in the article's Creative Commons licence, unless indicated otherwise in a credit line to the material. If material is not included in the article's Creative Commons licence and your intended use is not permitted by statutory regulation or exceeds the permitted use, you will need to obtain permission directly from the copyright holder. To view a copy of this licence, visit http://creativecommons.org/licenses/by/4.0/.

\section{References}

1. Dyer M, Ögmundardóttir H (2018) Transition of Vaxjo and Sonderborg towards becoming fossil fuel-free communities. Proc Inst Civil Engine Energy. 171(1):3-11

2. Christchurch City Council. (2011). Common Themes from Public Ideas Christchurch Central City Plan.

3. Dyer, M. Corisini, F., Certoma, C. (2017). Making urban design a public participatory goal: toward evidence-based urbanism. ICE Proceedings Urban Design and Planning.

4. Pearce D, Turner R (1989) Economics of natural resources and the environment. Johns Hopkins University Press, Baltimore

5. Preston, F., 2012. A Global Redesign? Shaping the Circular Economy. Available at http://www.ecoconnect. org.uk/download/Shaping the Circular Economy.pdf.

6. Geissdoerfer M, Savaget P, Bocken N, Hultink E (2016) The Circular Economy e A new sustainability paradigm? J Cleaner Prod 143(2017):757-768

7. European Commission, 2014. Towards a Circular Economy: a Zero Waste Programme for Europe, Communication from the Commission to the European Parliament, the Council, the European Economic and Social Committee and the Committee of the Regions. European Commission, Brussels.

8. European Commission, 2015. Closing the Loop - an EU Action Plan for the Circular Economy, Com(2015) 614 Communication from the Commission to the European Parliament, the Council, the European Economic and Social Committee and the Committee of the Regions. European Commission, Brussels.

9. Ghisellini, P., Cialani, C., Ulgiati, S. 2016. A review on circular economy: the expected transition to a balanced interplay of environmental and economic systems. J Cleaner Prod 114 (2016) pp11-32, 11

10. Kirchherr J, Reike D, Hekkert M (2017) 2017. Conceptualizing the circular economy: an analysis of 114 definitions. Resour Conserv Recyc 127:221-232

11. Su B, Heshmati A, Geng Y, Yu X (2013) A review of the circular economy in China: moving from rethoric to implementation. J. Clean. Prod. 42:215-277

12. Yuan Z, Bi J, Moriguichi Y (2006) The circular economy; a new development strategy in China. J. Ind. Ecol. 10:4-8

13. Van Berkel R, Fujita T, Hashimoto S, Geng Y (2009) Industrial and urban symbiosis in Japan: analysis of the Eco-Town program 1997e2006. J. Environ. Manag. 90:1544-1556

14. Potting, J., Hekkert, M., Worrell, E. and Hanemaaijer, A. 2017. Circular economy: measuring innovation in the product chain. Policy Report. PBL Netherlands Environmental Assessment Agency. PBL publication number: 2544. The Hague.

15. Dyer M, Gleeson D, Ogmundadottir H, Gammelgaard Ballantyne A, and Bolving K. 2016. Awareness, communication and visualisation for transition to Triple Zero energy water and waste. Goodsite, ME and Juhola S (eds). 2016. Green Defence. NATO Science for Peace and Security Series. Springer: Dordrecht. Chapter 14.

16. Fung A (2003) Survey Article: Recipes for public spheres: eight institutional design choices and their consequences. The Journal of Political Philosophy 11(3):338-367 
17. Fung A (2006) Varieties of participation in complex governance. Pub Administr Rev 66(1):66-75

18. Nabatchi T (2012) Putting the "public" back in public values research: designing participation to identify and respond to values. Public Administration Review 72(5):699-708

19. Gleeson, R. and Dyer, M. (2017). Manifesto for Collaborative Urbanism. Eds. Certomà, C., Dyer, M., Pocatilu, L., \& Rizzi, F. Citizen empowerment and innovation in the data-rich city. Chp 1, pp 3-18. Springer Publication.

20. Sanders EB-N, Pieter Jan S (2008) Co-creation and the new landscapes of design. Co-Design. 4:5-18

21. Ehn, P. (2008). DOC and the power of things and representatives. In: Costa CJ, Protopsaltis A, Aparicio M, ONeill H (eds.) Proceedings of the 26th ACM international conference on design of communication, pp 3132

22. Dewey (1981). Dewey, John. The Public and Its Problems. Vol. 2 of The Later Works of John Dewey, 1925 - 1953, edited by Jo Ann Boydston. Carbondale: Southern Illinois. University Press, $1981-90$.

23. Eisenstein $\mathbf{J}$ (2019) Introduction to natural language processing. MIT press

24. Hinton GE, Osindero S, Teh Y-W (2006) A fast learning algorithm for deep belief nets. Neural Computation 18(7):1527-1554

25. Manning CD (2015) Last words: computational linguistics and deep learning. Comput Linguis 41(4):701707. https://doi.org/10.1162/COLI_a_00239

26. Gildea D, Jurafsky D (2002) Automatic labeling of semantic roles. Computational Linguistics 28(3):245288

27. Kalchbrenner, N., \& Blunsom, P. (2013). Recurrent continuous translation models. Proceedings of the 2013 Conference on Empirical Methods in Natural Language Processing, 1700-1709.

28. Manning, C. D., Surdeanu, M., Bauer, J., Finkel, J., Bethard, S. J., \& McClosky, D. (2014). The Stanford CoreNLP Natural Language Processing Toolkit. Association for Computational Linguistics (ACL) System Demonstrations, 55-60. Retrieved from http://www.aclweb.org/anthology/P/P14/P14-5010

29. Socher, R., Bauer, J., Manning, C. D., \& Ng, A. Y. (2013a). Parsing with compositional vector grammars. Proceedings of the 51st Annual Meeting of the Association for Computational Linguistics (Volume 1: Long Papers), 455-465. Sofia, Bulgaria: Association for Computational Linguistics. Retrieved from https://www. aclweb.org/anthology/P13-1045

30. Fares M, Kutuzov A, Oepen S, Velldal E (2017) Word vectors, reuse, and replicability: towards a community repository of large-text resources. Proceedings of the 21 st Nordic Conference on Computational Linguistics, 271-276. Gothenburg, Sweden: Association for Computational Linguistics. Retrieved from https://www.aclweb.org/anthology/W17-0237

31. Dyer M, Dyer R, Weng M-H, Wu S, Garcia FT (2019) Framework for soft and hard city infrastructures. ICE Proc Urban Design Plan. 172(6):219-227

32. Brand D, Nicholson H (2016) Public space and recovery: learning from post-earthquake Christchurch. Journal of Urban Design 21(2):159-176

33. Gjerde M (2017) Building back better: learning from the Christchurch Rebuild. Procedia Eng 198:530 540. https://doi.org/10.1016/j.proeng.2017.07.108

34. Simons G (2016) Projecting failure as success: residents' perspectives of the Christchurch earthquakes recovery. Cogent Social Sciences. 2016(2):1-22 